\title{
CONTROLE DE PLANTAS DANINHAS NACULTURADO MILHO UTILIZANDO LEUCENA (Leucaena leucocephala (LAM.) DE WIT)
}

\author{
HÉLIO TEIXEIRA PRATES ${ }^{1}$, NÁDJA DE MOURA PIRES², ISRAEL ALEXANDRE PEREIRA \\ FILHO $^{1}$
}

\author{
${ }^{1}$ Pesquisadores, Embrapa Milho e Sorgo. Caixa Postal 151, CEP 35701-970 Sete Lagoas, MG. E-mail: \\ htprates@cnpms.embrapa.br (autor paracorrespondência) \\ ${ }^{2}$ Bolsista Recém-Doutor, CNPq.
}

Revista Brasileira de Milho e Sorgo, v.2, n.2, p.36-43, 2003

\begin{abstract}
RESUMO - Avaliou-se o efeito da parte aérea da leucena, em condições de casa de vegetação e campo, sobre o desenvolvimento de plantas daninhas, fitotoxicidade para o milho e acréscimo de nitrogênio para a cultura. Em casa de vegetação (vasos) foram avaliadas 25 tha $^{-1} \mathrm{da}$ parte aérea da leucena incorporada e colocada em cobertura. Após a distribuição da leucena nos vasos, seguiu-se o plantio do milho 5, 10, 20 e 40 dias. Em condições de campo, foram avaliados 20,30 e $40 \mathrm{t} \mathrm{ha}^{-1}$ de matéria verde em cobertura e incorporada. A leucena, em casa de vegetação, inibiu o desenvolvimento das plantas daninhas, não apresentando fitotoxicidade para o milho. Em condições de campo, $40 \mathrm{t} \mathrm{ha}^{-1}$ de leucena em cobertura controlaram o desenvolvimento das plantas daninhas sem prejudicar o rendimento de grãos de milho.
\end{abstract}

Palavras-chave: leucena incorporada, leucena em cobertura, alelopatia, Zea mays L.

\section{WEED CONTROL IN MAIZE CROP USING LEUCAENA (Leucaena leucocephala (LAM.) DE WIT)}

\begin{abstract}
In this work, the effects of leucaena shoots were assessed in greenhouse and field experiments against weeds of maize crop, phytoxicity on maize plant and nitrogen incorporation in the crop. In greenhouse bioassay (pots) leucaena shoots $\left(25 \mathrm{tha}^{-1}\right)$ were evaluated both incorporated and as mulch in the soil, followed by maize sowing at 5, 10, 20 and 40 days after leucaena application. Field experiment was carried out with 20,30 and 40 ha $^{-1}$ of fresh leucaena shoots material used both incorporated and as mulch in soil. In the field $40 \mathrm{t}$ ha $^{-1}$ of leucaena as mulch the weed population was controlled without any damage to the maize grain yield. In greenhouse it was observed inhibition of weed development with no phytotoxicity to maize.
\end{abstract}

Key words: incorporated leucaena, mulch, allelopathy, Zea mays L.

A leucena é uma leguminosa perene, originária do México, encontrada em toda a região tropical. Apresenta crescimento rápido, sistema radicular profundo, sendo capaz de fixar até 600 kg.ha ${ }^{-1}$ por ano de nitrogênio, em simbiose com bactérias do gênero Rhizobium (Rosenthal, 1982), o que proporciona ao produtor economia na adubação nitrogenada. Além disso, a leucena é utilizada como fonte protéica na alimentação animal e no reflorestamento de áreas com solos degradados, melhorando, dessa forma, suas propriedades físicoquímicas e biológicas (Karim et al., 1991; Larbi et al., 1993; Salazar et al., 1993; Mjema-Maweta et al., 1995). 
Outro aspecto que vem sendo discutido na literatura é a utilização da leucena em cobertura ou incorporada ao solo para o controle de plantas daninhas nas culturas, pois a decomposição da parte aérea pode liberar substâncias tóxicas produzidas pelo metabolismo secundário da planta, capazes de interferir no desenvolvimento de outras plantas (Budelman, 1988; Salazar, et al., 1993; Akobundu et al., 1999; Pires et al., 2001).

O extrato aquoso das folhas da leucena apresenta fitotoxicidade sobre várias plantas e os aleloquímicos envolvidos nesse efeito são a mimosina $\{\beta-[N-(3-h i d r o x i-4-o x$ opiridil $)]-\alpha-$ aminopropiônico\}, quercetina, ácido gálico e os ácidos protocatecuico, $p$-hidroxibenzóico, $p$ hidroxifenilacético, vanílico, ferúlico, caféico e $p$ cumárico, conforme estudos realizados por Chou \& Kuo (1986). Dentre essas substâncias, o potencial alelopático da leucena é atribuído principalmente ao aleloquímico mimosina, devido à presença de um grupo hidroxila na posição três e de um oxigênio na posição quatro do anel piridínico (Ward \& Harris, 1976).

Neste estudo, foram avaliados, em casa de vegetação e campo, o efeito da leucena sobre o controle de plantas daninhas na cultura do milho e a fitotoxicidade da leucena sobre o milho.

\section{Material e Métodos}

Os experimentos em casa de vegetação e de campo foram conduzidos na Embrapa Milho e Sorgo, localizada em Sete Lagoas, MG, Brasil, em solo classificado como latossolo vermelho distrófico típico, adubado de acordo com a análise química, realizada no Laboratório de Solos e Nutrição de Plantas da Embrapa Milho e Sorgo, e a necessidade da cultura, sendo utilizada a cultivar de milho BR 3123 .

\section{Experimento em casa de vegetação}

O solo para o experimento foi coletado no mesmo local onde se realizou o ensaio de campo e distribuído em vaso de plástico, com de 3 L de capacidade. A parte aérea (folhas e caules tenros) da leucena foi incorporada ou colocada na superfície do solo, na proporção de 25 tha $^{-1}$. Essa quantidade foi estabelecida conforme ensaios preliminares realizados por Prates et al. (1999), em que foram estudadas diferentes quantidades da parte aérea da leucena e seu efeito na cultura do milho. Os tratamentos desse bioensaio consistiram da combinação do modo de adição da leucena (incorporada e na superfície), em quatro épocas de semeadura do milho $(5,10,20$ e 40 dias após a adição da leucena), comparados com o tratamento sem leucena, utilizando delineamento experimental em blocos ao acaso, com três repetições. A umidade dos vasos foi mantida na capacidade de campo, por meio de pesagens diárias, de modo a repor as perdas por evapotranspiração.

Vinte dias após a adição da parte aérea da leucena, foi realizada a contagem das plantas daninhas existentes no solo utilizado, separando-se folhas largas de folhas estreitas. Observou-se que as plantas daninhas de maior ocorrência foram: Brachiaria decumbens, Portulaca oleracea, Bidens pilosa e Amaranthus hibridus. A parte aérea das plantas daninhas foi seca a $70^{\circ} \mathrm{C}$ por $72 \mathrm{~h}$, para determinação da matéria seca.

A fitotoxicidade da leucena sobre o milho foi avaliada de três em três dias, após sua germinação, durante 21 dias, baseando-se na escala de notas do Conselho Europeu de Pesquisa sobre Plantas Daninhas - EWRC (Frans, 1972), modificada. Em seguida, essas plantas foram colhidas e avaliadas quanto à altura, peso da matéria seca da parte aérea e das raízes, e teor de nitrogênio nas folhas do milho, utilizando-se metodologia descrita por Zagatto et al. (1981).

\section{Experimento de campo}

Para avaliar o efeito da parte aérea da leucena no desenvolvimento de plantas daninhas e 
do milho em campo, o delineamento experimental consistiu de oito tratamentos, dispostos em blocos ao acaso, com quatro repetições. O tamanho da parcela foi de 2,4 x 5,0 m. Os tratamentos foram: três quantidades de matéria fresca da parte aérea da leucena (20, 30 e 40 t ha $\left.^{-1}\right)$, incorporadas e em cobertura no solo, e as testemunhas capinada e sem capina manual das plantas daninhas. Nas parcelas com leucena incorporada, o milho foi semeado cinco dias após a adição e, em cobertura, a leucena foi colocada no solo com a planta de milho no estádio de cinco folhas.

Mensalmente, foram realizadas as avaliações de identificação e contagem das plantas daninhas presentes em um metro quadrado, na área útil da parcela, assim como avaliações da fitotoxicidade da leucena sobre o milho, utilizando-se a escala de notas EWRC (Frans, 1972), modificada. A percentagem de controle das plantas daninhas foi calculada em função da quantidade de plantas daninhas existentes em relação à testemunha sem capina.

$\mathrm{Na}$ avaliação, em campo, da parte aérea da leucena no desenvolvimento de plantas daninhas e do milho, verificou-se que as espécies de plantas daninhas predominantes foram: Brachiaria plantaginea, Cenchrus echinatus, Amaranthus hybridus, Siegesbeckia orientalis e Nicandra physaloides.

No estádio de oito folhas e na época do florescimento, foram realizadas análises das seguintes características na cultura do milho: altura das plantas (medida tomada do solo até a folha bandeira, após maturação fisiológica), área foliar (medida em integrador de área foliar da LICOR, modelo LI 3100), diâmetro do colmo (medida tomada com paquímetro digital), matéria seca da parte aérea e teor de nitrogênio na folha, conforme descrito por Silva (1981). Na época da colheita, foram determinados a produção de grãos e o teor de nitrogênio.

\section{Análise estatística}

Para a interpretação dos resultados dos experimentos, os dados foram submetidos à análise de variância (ANOVA) e testes de médias, sendo os valores de contagem das plantas daninhas transformados em $\sqrt{\mathrm{x} \quad 0,5}$.

\section{Resultados e Discussão}

\section{Experimento em casa de vegetação}

Os resultados mostrados na Tabela 1 indicaram que a adição de $25 \mathrm{t} \mathrm{ha}^{-1}$ de leucena favoreceu o controle de algumas plantas de folhas largas e gramíneas. A incorporação da leucena ao solo promoveu controle semelhante ao tratamento com leucena na superfície, com relação a folhas largas; entretanto, houve um estímulo de germinação das gramíneas $B$. decumbes e $B$. pilosa.

Verifica-se, pela Tabela 2, que aos 20 dias após a aplicação da leucena incorporada, $56,78 \%$ de folhas largas foram controladas não sendo eficiente no controle de gramíneas, enquanto que o uso da leucena na superfície do solo proporcionou um controle de 59,71\% de folhas largas e 57,51\% de gramíneas em relação ao tratamento sem leucena. Observou-se, no tratamento em que a leucena foi incorporada, que houve maior presença de $B$. decumbens, devido, provavelmente, à redução na competição entre as plantas daninhas, quando comparada com o tratamento sem adição de leucena.

Em geral, a adição da parte aérea da leucena ao solo proporcionou menor desenvolvimento das plantas daninhas, o que pode ser verificado pela menor produção de matéria seca das plantas, em relação ao tratamento sem leucena. Esse resultado, provavelmente, ocorreu devido aos efeitos físicos da cobertura e alelopático, conforme observado por Chou \& Kuo (1986) e Budelman (1988).

A quantidade de leucena utilizada no solo não mostrou efeito fitotóxico sobre as plantas de milho (Tabela 3); ao contrário, aos 20 dias, mostrou estímulo 
TABELA 1. Número médio de espécies daninhas obtido aos 20 dias após a germinação do milho BR 3123. Embrapa Milho e Sorgo, Sete Lagoas, MG, 2001.

\begin{tabular}{lcccc}
\hline Tratamentos & B. decumbens & P. oleracea & B. pilosa & A. hybridus. \\
\hline Sem leucena & $18,67 \mathrm{~b}$ & $2,92 \mathrm{a}$ & $0,17 \mathrm{a}$ & $10,33 \mathrm{a}$ \\
Leucena incorporada & $25,33 \mathrm{a}$ & $0,42 \mathrm{~b}$ & $0,33 \mathrm{a}$ & $3,16 \mathrm{~b}$ \\
Leucena em Cobertura & $6,25 \mathrm{c}$ & $0,58 \mathrm{~b}$ & $0,08 \mathrm{a}$ & $6,25 \mathrm{ab}$ \\
\hline CV $(\%)$ & 19,16 & 39,26 & 28,75 & 29,83 \\
\hline
\end{tabular}

Médias seguidas de mesma letra, na coluna, não diferem estatisticamente entre si, pelo teste de Tukey, a 5\%.

TABELA 2. Número ( $\left.\mathrm{N}^{\circ}\right)$ e matéria seca (MS) das plantas daninhas, avaliadas aos 20 dias após a germinação. Embrapa Milho e Sorgo, Sete Lagoas, MG, 2001.

\begin{tabular}{|c|c|c|c|c|c|c|}
\hline \multirow[b]{2}{*}{ Tratamentos } & \multicolumn{2}{|c|}{ Folhas Largas } & \multicolumn{2}{|c|}{ Gramíneas } & \multicolumn{2}{|c|}{ Total } \\
\hline & $\mathrm{N}^{0}$ & MS (g) & $\mathrm{N}^{0}$ & MS (g) & $\mathrm{N}^{0}$ & MS (g) \\
\hline er & $27,3 \mathrm{a}$ & $2,52 \mathrm{a}$ & $19,3 \mathrm{a}$ & 3,2 & $46,6 \mathrm{a}$ & $5,73 \mathrm{a}$ \\
\hline Lel & $11,8 \mathrm{~b}$ & $0,43 \mathrm{~b}$ & 27,9 a & $4,23 \mathrm{a}$ & $39,7 \mathrm{a}$ & $4,66 \mathrm{ab}$ \\
\hline Leucena $\epsilon$ & $11,0 \mathrm{~b}$ & $1,32 \mathrm{~b}$ & $8,2 \mathrm{~b}$ & $2,62 \mathrm{~b}$ & $19,2 \mathrm{~b}$ & $3,94 \mathrm{~b}$ \\
\hline$\overline{C V}(\%)$ & 19,89 & 67,56 & 20,97 & 34,62 & 15,38 & 25,18 \\
\hline
\end{tabular}

Médias seguidas de mesma letra, dentro de cada tratamento, não diferem estatisticamente entre si, pelo teste de Tukey, a $5 \%$.

TABELA 3. Matéria seca da parte aérea (A), raízes $(R)$ e total $(T)$ e altura das plantas $(H)$ de milho BR 3123, analisadas nos tratamentos com leucena. Embrapa Milho e Sorgo, Sete Lagoas, MG, 2001.

\begin{tabular}{lcccc}
\hline Tratamentos & $\mathrm{A}$ & $\mathrm{R}$ & $\mathrm{T}$ & $\mathrm{H}$ \\
& $(\mathrm{g})$ & $(\mathrm{g})$ & $(\mathrm{g})$ & $(\mathrm{cm})$ \\
\hline Sem leucena & $6,92 \mathrm{~b}$ & $3,59 \mathrm{a}$ & $10,52 \mathrm{~b}$ & $74,67 \mathrm{a}$ \\
Leucena incorporada & $8,35 \mathrm{ab}$ & $3,43 \mathrm{a}$ & $11,78 \mathrm{ab}$ & $75,83 \mathrm{a}$ \\
Leucena na superfície & $8,96 \mathrm{a}$ & $3,99 \mathrm{a}$ & $12,94 \mathrm{a}$ & $71,67 \mathrm{a}$ \\
\hline $\mathrm{CV}(\%)$ & 8,81 & 12,02 & 8,12 & 6,99 \\
\hline
\end{tabular}

Médias seguidas de mesma letra, na coluna, não diferem estatisticamente entre si, pelo teste de Tukey, a 5\%.

no crescimento da parte aérea. Não houve interação significativa entre modo de adição de leucena (incorporada e cobertura) e período de plantio do milho, após aplicação de leucena ao solo. Entretanto, comparando-se o modo de adição da leucena, verificou-se que a mesma favoreceu o desenvolvimento da parte aérea das plantas de milho (Tabela 3) e este foi maior quando o período em que foi adicionada a leucena ao solo foi aos 20 e 40 dias (Tabela 4). Provavelmente, isso ocorreu devido à decomposição do material, favorecendo maior disponibilidade de nitrogênio e, conseqüentemente, melhor desempenho da cultura (Salazar et al., 1993).

A Tabela 5 mostra que a leucena adicionada ao solo, cinco e dez dias antes do plantio do milho, não trouxe nenhum acréscimo de nitrogênio para 
a cultura, quando avaliada 20 dias após a germinação. Por outro lado, o uso da leucena 20 dias antes do plantio do milho resultou em maior teor de nitrogênio, em relação às plantas cultivadas sem leucena, sugerindo que a leucena estaria fornecendo nitrogênio para a cultura. Estudo conduzido por Pereira Filho et al. (1996) mostrou que a leucena substitui totalmente o nitrogênio no cultivo do milho, com um suprimento da ordem de $95 \mathrm{~kg} \mathrm{ha}^{-1}$. Entretanto, a adição da leucena 40 dias antes do plantio do milho apenas favoreceu a cultura quando incorporada ao solo; isso possivelmente ocorreu por que não houve perda do nitrogênio durante o processo de decomposição. As plantas de milho apresentaram maior teor de nitrogênio quando a leucena foi incorporada ao solo 20 e 40 dias antes do plantio; por outro lado, quando colocada em cobertura, o melhor efeito ocorreu aos dez dias após a adição.

\section{Experimento de campo}

Não se observou diferença significativa na densidade de gramíneas em relação à testemunha sem capina, mas houve redução das folhas largas quando a leucena foi adicionada ao solo em cobertura, tendo a menor densidade de plantas daninhas sido observada na quantidade de $40 \mathrm{tha}^{-1}$ da parte aérea da leucena (Tabela 6).

Observou-se que houve um efeito crescente da eficiência de controle das plantas daninhas com o aumento da quantidade da leucena aplicada ao solo, tanto incorporada como em cobertura, em relação à testemunha sem capina (Tabela 7). Nota-se, portanto, que a leucena pode ter reduzido a população de plantas daninhas, devido à liberação para o solo de substâncias com ação alelopática (Akobundu et al., 1999; Chou \& Kuo, 1986), além do efeito físico de cobertura do solo.

TABELA 4. Médias das características biomassa da parte aérea (A), raízes (R) e total (T) e altura das plantas (H) de milho BR 3123, analisadas após adição da leucena ao solo. Embrapa Milho e Sorgo, Sete Lagoas, MG, 2001.

\begin{tabular}{ccccc}
\hline Período de adição (dias) & $\begin{array}{c}\mathrm{A} \\
(\mathrm{g})\end{array}$ & $\begin{array}{c}\mathrm{R} \\
(\mathrm{g})\end{array}$ & $\begin{array}{c}\mathrm{T} \\
(\mathrm{g})\end{array}$ & $\begin{array}{c}\mathrm{H} \\
(\mathrm{cm})\end{array}$ \\
\hline 5 & $6,59 \mathrm{~b}$ & $3,92 \mathrm{a}$ & $10,51 \mathrm{~b}$ & $66,44 \mathrm{~b}$ \\
10 & $6,95 \mathrm{~b}$ & $3,19 \mathrm{a}$ & $10,14 \mathrm{~b}$ & $63,44 \mathrm{~b}$ \\
20 & $9,40 \mathrm{a}$ & $3,86 \mathrm{a}$ & $13,26 \mathrm{a}$ & $83,33 \mathrm{a}$ \\
40 & $9,37 \mathrm{a}$ & $3,71 \mathrm{a}$ & $13,08 \mathrm{a}$ & $83,00 \mathrm{a}$ \\
\hline CV $(\%)$ & 8,81 & 12,02 & 8,12 & 6,99 \\
\hline
\end{tabular}

Médias seguidas de mesma letra, na coluna, não diferem estatisticamente entre si, pelo teste de Tukey, a 5\%.

TABELA 5. Teor de nitrogênio (\%) nas folhas de milho BR 3123 aos 20 dias após a germinação, semeado aos 5, 10, 20 e 40 dias após a adição da leucena ao solo. Embrapa Milho e Sorgo, Sete Lagoas, MG, 2001.

\begin{tabular}{lcccc}
\hline \multirow{2}{*}{ Modo de adição da leucena } & \multicolumn{4}{c}{ Época de semeadura do milho (dias) } \\
\cline { 2 - 5 } & 5 & 10 & 20 & 40 \\
\hline Sem leucena & 2,547 a A & 2,747 a A & 2,760 b A & 2,990 ab A \\
Leucena incorporada & 2,730 a B & 3,153 a AB & 3,340 a A & 3,417 a A \\
Leucena em cobertura & 2,690 a B & 3,210 a A & $2,937 \mathrm{ab} \mathrm{AB}$ & 2,543 b B \\
\hline CV $(\%)$ & \multicolumn{5}{c}{8,01} \\
\hline
\end{tabular}

Médias dentro das colunas, seguidas pelas mesmas letras minúsculas e dentro das linhas, seguidas pelas mesmas letras maiúsculas, não diferem entre si, pelo teste de Tukey, a $5 \%$. 
Os tratamentos mais eficientes no controle de gramíneas foram leucena incorporada $\left(40 \mathrm{tha}^{-1}\right)$ e em cobertura ( 30 e $40 \mathrm{t} \mathrm{ha}^{-1}$ ), com aproximadamente 15,41 e $65 \%$ de controle, respectivamente, em relação à testemunha capinada (Tabela 7). Para as folhas largas, os tratamentos em cobertura, nas quantidade de 30 e 40 t ha $^{-1}$, foram os mais eficientes, com 57 e $71 \%$ de controle, respectivamente.

O uso da leucena no solo, tanto incorporada como em cobertura, não provocou efeito fitotóxico sobre o desenvolvimento e a produção do milho (Tabela 8). Neste trabalho, observou-se que houve uma tendência de maior produção do milho nos tratamentos com a adição da leucena, exceto no tratamento com 20 tha $^{-1}$ de leucena em cobertura. Isso provavelmente ocorreu devido à maior competição das plantas daninhas com a cultura (Tabela 8). O tratamento com a adição da leucena em cobertura na quantidade de $40 \mathrm{t} \mathrm{ha}^{-1}$ apresentou, em geral, o melhor controle das plantas daninhas,

TABELA 6. Densidade média (por $\mathrm{m}^{2}$ ) das plantas daninhas, marmelada (Mar), timbete (Tim), total de gramíneas (Tgr), caruru (Car), botão de ouro (Bou), joá de capote (Joa) e total de folhas largas (Tfl), aos 60 dias após a incorporação e 40 dias após a cobertura do solo com leucena. Embrapa Milho e Sorgo, Sete Lagoas, MG, 2001.

\begin{tabular}{|c|c|c|c|c|c|c|c|}
\hline \multirow{2}{*}{ Tratamentos } & \multicolumn{3}{|c|}{ Gramíneas } & \multicolumn{4}{|c|}{ Folhas Largas } \\
\hline & Mar & Tim & Tgr & Car & Bou & Joa & Tfl \\
\hline Incorporado $\left(20 \mathrm{t} \mathrm{ha}^{-1}\right)$ & $3 \mathrm{a}$ & $2 \mathrm{a}$ & $10 \mathrm{a}$ & 5 bcd & $9 \mathrm{a}$ & $11 \mathrm{a}$ & $39 \mathrm{a}$ \\
\hline Incorporado $\left(30 \mathrm{t} \mathrm{ha}^{-1}\right)$ & $3 \mathrm{a}$ & $3 \mathrm{a}$ & $8 \mathrm{a}$ & $8 a b c$ & $6 \mathrm{a}$ & $13 \mathrm{a}$ & $35 \mathrm{ab}$ \\
\hline Incorporado $\left(40 \mathrm{t} \mathrm{ha}^{-1}\right)$ & $2 a b$ & $2 \mathrm{a}$ & $7 \mathrm{a}$ & $20 \mathrm{a}$ & $4 a b$ & $4 \mathrm{ab}$ & $32 \mathrm{ab}$ \\
\hline Cobertura $\left(20 \mathrm{t} \mathrm{ha}^{-1}\right)$ & $1 \mathrm{ab}$ & $2 \mathrm{a}$ & $6 a$ & $7 \mathrm{abc}$ & $5 \mathrm{a}$ & $8 \mathrm{a}$ & $36 \mathrm{ab}$ \\
\hline Cobertura $\left(30 \mathrm{t} \mathrm{ha}^{-1}\right)$ & $1 \mathrm{ab}$ & $2 \mathrm{a}$ & $4 a b$ & $4 \mathrm{bcd}$ & $5 \mathrm{a}$ & $5 \mathrm{ab}$ & $18 \mathrm{bc}$ \\
\hline Cobertura $\left(40 \mathrm{t} \mathrm{ha}^{-1}\right)$ & $1 \mathrm{ab}$ & $0 \mathrm{a}$ & $5 \mathrm{ab}$ & $1 \mathrm{~cd}$ & $4 \mathrm{ab}$ & $4 \mathrm{ab}$ & $14 \mathrm{c}$ \\
\hline Testemunha sem capina & $2 a b$ & $1 \mathrm{a}$ & $6 \mathrm{a}$ & $15 \mathrm{ab}$ & $6 \mathrm{a}$ & $14 \mathrm{a}$ & $44 \mathrm{a}$ \\
\hline Testemunha capinada & $0 \mathrm{~b}$ & $0 \mathrm{a}$ & $0 \mathrm{~b}$ & $0 \mathrm{~d}$ & $0 \mathrm{~b}$ & $0 \mathrm{~b}$ & $0 \mathrm{~d}$ \\
\hline CV (\%) & 36,75 & 48,44 & 38,00 & 46,48 & 42,88 & 44,53 & 24,86 \\
\hline
\end{tabular}

Médias seguidas de mesma letra, na coluna, não diferem significativamente pelo teste Duncan, a 5\%.

TABELA 7. Controle de plantas daninhas 60 dias após a incorporação e 40 dias após a cobertura do solo com leucena. Embrapa Milho e Sorgo, Sete Lagoas, MG, 2001.

\begin{tabular}{|c|c|c|}
\hline \multirow{2}{*}{ Tratamentos } & \multicolumn{2}{|c|}{ Controle (\%) } \\
\hline & Gramíneas & Folhas Largas \\
\hline Incorporado $\left(20 \mathrm{t} \mathrm{ha}^{-1}\right)$ & $0,00 \mathrm{~d}$ & $10,38 \mathrm{c}$ \\
\hline Incorporado $\left(30 \mathrm{tha}^{-1}\right)$ & $0,00 \mathrm{~d}$ & $14,73 \mathrm{c}$ \\
\hline Incorporado $\left(40 \mathrm{t} \mathrm{ha}^{-1}\right)$ & $14,58 \mathrm{~cd}$ & $25,44 \quad \mathrm{c}$ \\
\hline Cobertura $\left(20 \mathrm{t} \mathrm{ha}^{-1}\right)$ & $0,00 \mathrm{~d}$ & $13,58 \quad \mathrm{c}$ \\
\hline Cobertura $\left(30 \mathrm{t} \mathrm{ha}^{-1}\right)$ & $40,63 \mathrm{bc}$ & $56,92 \mathrm{~b}$ \\
\hline Cobertura $\left(40 \mathrm{t} \mathrm{ha}^{-1}\right)$ & $65,18 \mathrm{~b}$ & $70,87 \mathrm{~b}$ \\
\hline Testemunha sem capina & $0,00 \mathrm{~d}$ & $0,00 \mathrm{c}$ \\
\hline Testemunha capinada & $100,00 \mathrm{a}$ & $100,00 \mathrm{a}$ \\
\hline CV (\%) & 80,49 & 38,60 \\
\hline
\end{tabular}

Médias seguidas de mesma letra, na coluna, não diferem significativamente pelo teste Duncan, a 5\%. 
TABELA 8. Valores médios da altura (AL) e diâmetro (DIA) da planta de milho, altura da espiga (ALE) e produção de grãos por hectare (PG), avaliados na época da colheita. Embrapa Milho e Sorgo, Sete Lagoas, MG, 2001.

\begin{tabular}{lcccc}
\hline \multirow{2}{*}{ Tratamentos } & \multicolumn{4}{c}{ Características Avaliadas } \\
\cline { 2 - 5 } & AL $(\mathrm{m})$ & DIA $(\mathrm{cm})$ & ALE $(\mathrm{m})$ & PG $\left(\mathrm{kg} \mathrm{ha}^{-1}\right)$ \\
\hline Incorporado $\left(20 \mathrm{t} \mathrm{ha}^{-1}\right)$ & $2,17 \mathrm{ab}$ & $39,50 \mathrm{ab}$ & $1,20 \mathrm{abc}$ & $7185,19 \mathrm{a}$ \\
Incorporado $\left(30 \mathrm{t} \mathrm{ha}^{-1}\right)$ & $2,23 \mathrm{a}$ & $40,24 \mathrm{ab}$ & $1,24 \mathrm{a}$ & $7643,45 \mathrm{a}$ \\
Incorporado $\left(40 \mathrm{t} \mathrm{ha}^{-1}\right)$ & $2,15 \mathrm{ab}$ & $37,61 \mathrm{~b}$ & $1,21 \mathrm{abc}$ & $7152,50 \mathrm{a}$ \\
Cobertura $\left(20 \mathrm{t} \mathrm{ha}^{-1}\right)$ & $2,13 \mathrm{ab}$ & $38,90 \mathrm{ab}$ & $1,14 \mathrm{abc}$ & $6205,51 \mathrm{a}$ \\
Cobertura $\left(30 \mathrm{t} \mathrm{ha}^{-1}\right)$ & $2,21 \mathrm{a}$ & $39,08 \mathrm{ab}$ & $1,22 \mathrm{ab}$ & $7152,25 \mathrm{a}$ \\
Cobertura $\left(40 \mathrm{t} \mathrm{ha}^{-1}\right)$ & $2,16 \mathrm{ab}$ & $41,16 \mathrm{a}$ & $1,15 \mathrm{abc}$ & $7756,19 \mathrm{a}$ \\
Testemunha capinada & $2,10 \mathrm{ab}$ & $40,06 \mathrm{ab}$ & $1,10 \mathrm{c}$ & $7826,08 \mathrm{a}$ \\
\hline $\mathrm{CV}(\%)$ & 4,12 & 4,31 & 5,53 & 17,06 \\
\hline
\end{tabular}

Médias seguidas de mesma letra, na coluna, não diferem significativamente pelo teste Duncan, a 5\%.

mostrando uma média de produção de grãos de milho semelhante à da testemunha capinada.

Dessa forma, as observações feitas no presente estudo concordam com a literatura (Budelman \& Vandapol, 1992, Prasad \& Subhashini, 1994, Kamara et al., 2000), ao afirmar que as interações alelopáticas devem ser investigadas criticamente para otimizar o múltiplo uso da leucena nos agroecossistemas.

\section{Conclusões}

Em casa de vegetação, a presença da leucena inibiu o desenvolvimento das plantas daninhas, sem causar efeito fitotóxico ao milho.

Em condições de campo, $40 \mathrm{t} \mathrm{ha}^{-1} \mathrm{de}$ leucena em cobertura controlaram o desenvolvimento das plantas daninhas, sem prejudicar o rendimento de grãos de milho.

\section{Agradecimento}

Ao laboratorista Nilson Machado Lopes, do Laboratório de Agroquímica da Embrapa Milho e Sorgo, a valiosa colaboração na condução dos bioensaios.

\section{Literatura Citada}

AKOBUNDU, I.O.; EKELEME, F.; CHIKOYE, $D$. Influence of fallow management systems and frequency of cropping on weed growth and crop yield. Weed Research, Oxford, v.39, p.241-256, 1999.

BUDELMAN, A. The performance of the leaf mulches of Leucaena leucocephla, Flemingia macrophyll and Gliricidia sepium in weed control. Agroforestry Systems, Dordrecht, v.6, p.137145, 1988.

BUDELMAN, A.; VANDAPOL, F. Farming system research and the quest for a sustainable agriculture. Agroforestry Systems, Dordrecht, v.19, p.187206, 1992.

CHOU, C.H.; KUO Y.L. Allelopathic research of subtropical vegetation in taiwan. III. Alelopathic exclusion of understory by Leucaena leucocephala (Lam.) de Wit. Journal of Chemical Ecology, New York, v.12, p.1431-1448, 1986.

FRANS, R.E. Measuring plant responses. In: WILKINSON, R.E. (Ed.). Research methods in weed science. [S.C.]: Southern Weed Science Society, 1972. p. 28-41. 
KAMARA, A.Y.; AKOBUNDU, I.O.; SANGINGA, N.; JUTZI, S.C. Effect of mulch from selected multipurpose trees (MPTs) on growth, nitrogen nutrition and yield of maize (Zea mays L.). Journal of Agronomy and Crop Science, Berlim, v.184, p.73-80, 2000.

KARIM,A.B.; SAVILL, P.S.; RHODES, E.R. The effect of young Leucaena leucocephala (Lam) De Wit hedges on the growth and yield of maize, sweet potato and cowpea in na agroforestry system in Sierra Leone. Agroforestry Systems, Dordrecht, v.16, p.203-211, 1991.

LARBI, .A.; JABBAR, M.A.;ATTA-KRAH,A.N.; COBBINA, J. Effect of taking a fodder crop on maize grain yield and soil chemical properties in Leucaena and Gliricidia alley farming systems in western Nigeria. Experimental Agriculture, London, v.29, p.317-321, 1993.

MJEMA-MAWETA, W.J.; MTIMUNI, J.P.; KAMWANJA, L.A. The effect of leucaena and /or maize bran (Madeya) supplementation of goats grazing star grass (Cynodon nlemfuensis Vanderyst) on birth weight of kids. International Journal Animal Sciences, Haryana, v.10, p.3540, 1995.

PEREIRA FILHO, I.A.; COELHO, A.M.; CRUZ, J.C. Produtividade de milho na presença e ausência da leucena e níveis de nitrogênio. In: CONGRESSO NACIONAL DE MILHO E SORGO, 21., 1996, Londrina: Resumos... Londrina: IAPAR, 1996, p. 252.

PIRES, N.M.; PRATES, H.T.; PEREIRA FILHO, I.A; OLIVEIRAJR., R.S.; FARIA, T.C.L.Atividade alelopática da leucena sobre espécies de plantas daninhas. Scientia Agricola, Piracicaba, v.58, p.6165,2001 .

PRASAD, M.N.V.; SUBHASHINI, P. Mimosineinhibted seed germination, seedling growth, and enzymes of Oryza sativa L. Journal of Chemical Ecology, New York, v.20, p.1689-1696, 1994.

PRATES, H.T.; PEREIRA FILHO, I.A.; PAES, J.M.V.; PIRES, N.M.; MAGALHÃES, P.C. Efeito da parte aérea da leucena (Leucaena leucocephala (Lam) De Wit) sobre o desenvolvimento das plantas daninhas e do milho. Sete Lagoas: EMBRAPA-CNPMS, 1999. 2p. (EMBRAPA-CNPMS, Pesquisa emAndamento, 34).

ROSENTHAL, G.A. Plant nonprotein amino and imino acids. New York: Academic Press, 1982.273p.

SILVA, D.J. Análise de alimentos: métodos químicos e biológicos. Viçosa: UFV, 1981.166p.

SALAZAR, A.; SZOTT, L.T.; PALM, C.A. Croptree interactions in alley cropping systems on alluvial soils of the Upper Amazon Basin. Agroforestry Systems, Dordrecht, v.22, p.67-82, 1993.

WARD, K.A.; HARRIS, R.L.N. Inibition of wool follicle DNA synthesis by mimosine and related 4(1H)-pyridones. Australian Journal Biological Science, Victoria, v.29, p.189-196, 1976.

ZAGATTO, E.A.G.; JACINTHO, A.O.; REIS, B.F.; KRUG, F.J.; BERGAMIN FILHO, H.; PESSENDA, L.C.R.; MORTATTI, J.; GINÉ, M.F. Manual de análises de plantas e água empregando sistemas de injeção em fluxo. Piracicaba: USP, 1981. 45p. 